\title{
The Jordan Seismological Observatory
}

\author{
by
}

\author{
Robert L. Kovach ${ }^{1}$ \\ Gordon E. Andreasen ${ }^{2}$ \\ Mark E. Gettings ${ }^{3}$ \\ John H. Healy ${ }^{4}$
}

10 July 1986

${ }^{1}$ Department of Geophysics, Stanford University and U.S. Geological Survey, Menlo Park, California.

${ }^{2}$ U.S. Agency for International Development, Amman, Jordan.

${ }^{3}$ U.S. Geological Survey, Reston, Virginia.

${ }^{4}$ U.S. Geological Survey, Menlo Park, California.

U.S. Geological Survey

Open File Report 86-384

This report is preliminary and has not been edited or reviewed for conformity with

Geological Survey Standards and nomenclature 
Table of Contents

1. Introduction

2. Description of Seismic Network

3. Description of Automated Data Processing

4. Determination of Epicenters and Local Magnitudes

5. Overaii Seismicity Pattern

6. Conciusions and Recommendations

7. Acknowiedgments

8. References 
List of Figures

Figure 2-1: Location of Seismograph Stations of the Jordan 3 Seismological Observatory

Figure 2-2: Diagram of Radio Transmissions of the remote 6 Seismic Stations to the Jordan Seismological Observatory

Figure 3-1: Schematic Showing Data Flow Through the 10 Automatic Seismic System, Jordan Seismological Observatory

Figure 4-1: Preliminary Velocity-Depth Model used for 12 Hypocenter Locations in Jordan

Figure 5-1: Microseismicity of Western Jordan, April through 14 June 1985.

Figure 6-1: A Proposed Plan for Additional Stations to be Added 16 to the Jordan Seismological Observatory Network 


\section{List of Tables}

Table 2-1: Jordan Seismic Stations, Geographical Locations and 4 Elevations

Table 2-2: Radio Transmitter and Receiver Frequencies Assigned 5 to Selsmic Stations and Relays, Jordan Seismological Observatory 


\section{Introduction}

Although the mapped geology of Jordan is quite well known (Bender, 1974), the pattern of earthquake activity, in particular, its temporal and spatial characteristics and its relationship to the geologic and tectonic framework of Jordan have not been well documented; this is primarily due to the absence of a seismograph network in Jordan. Previous studies of the seismicity of this region have shown that much of the measured earthquake activity correlates well with the dominant tectonic feature of the area, the Dead Sea Rift (Arieh, 1967; Wu et al., 1973; BenMenahem et al., 1976)

Previous studies of the seismicity, however, suggest results which are not compatible with the inferred rate of slip that is occurring along the Dead Sea Rift plate boundary (Freund et al., 1968). That is, geological and magnetic evidence points to a relative rate of plate movement of 4-6 mm/yr along the rift boundary (Girdler and Styles, 1974; Hatcher et al., 1981), and a total strike-slip movement of approximately $107 \mathrm{~km}$ has been indicated by matching magnetic anomalies across the rift. On the other hand, the rate of slip calculated from seismic data as a function of time yields an average slip rate of $1 \mathrm{~mm} / \mathrm{yr}$ (Kovach, 1979; Ben-Menahem, 1981ab). One is therefore forced to conclude that the region is probably accumulating strain energy for a future large earthquake. Other explanations, that the opening of the Red Sea has slowed significantly in historic time or that strain is being released as aseismic slip (North, 1974) or distributed slip (Kovach et al., 1985), are considered less likely.

In 1983 the Government of Jordan established an 8-station seismic network in northwest Jordan to monitor earthquake events and to assess the overall pattern of earthquake activity and seismic risk. The array of eight seismometers extends from the Makawir area northwards to the region near Jarash (see Figure 2-1). The seismic data are telemetered via FM transmission on assigned frequencies to the Natural Resources Authority in Amman where the data are displayed on conventional analog drum recorders. The analog system operates in parallel with an automated computer system that analyzes seismic events with a minimum demand on human resources.

\section{Description of Seismic Network}

The array of eight stations forming the core of the Jordan seismic network extends from the Makawir area north to the vicinity of Jarash (see Figure 2-1). Four stations are located in the vicinity of the King Talal dam: Burma (BURJ), Jarash (JARJ), Sumiya (SMAJ) and Er Rumman (RUMJ). These stations are referred to as the North Array. The remaining four stations, called the South Array, are located near Salt (SALJ), Kafrein (KFNJ), Maslubiya (MASJ) and Makawir 
(MKRJ). The geographic coordinates and station elevations are shown in Table 2-1. The coordinates and elevations were taken from 1:50,000 topographic maps of Jordan prepared for the Ministry of Economy and the United States Agency for International Development in Jordan. Latitudes and longitudes are believed to be accurate to within \pm 0.01 degrees and elevations to \pm 5 meters. The 1-hertz vertical-component seismometers are encased in covered concrete cylinders and cemented to bedrock. Each site is enclosed with protective fencing, and the transmitter and receiver equipment is housed in a locked wooden box with a steel roof for isolation from moisture and excessive heat. The antennas and solar panels are mounted on a 3-meter mast within the enclosure. The voltage-controlled oscillators (VCO's) for each seismometer are buried separately to minimize interference. The stations are regularly inspected for any obvious damage and repaired as required.

Line-of-sight radio transmission of the seismic data employs eight FM transmitters operating in the MegaHertz band from 168.800 to $172.700 \mathrm{MHz}$. Power is supplied to both receivers and transmitters by solar panels and batteries. The antennas are specially designed Yagi-type which are highly directional with a gain of $9 \mathrm{~dB}$. The subcarrier oscillator frequencies are within the audible band and range from 680 to $3060 \mathrm{~Hz}$. Details of the radio frequency distribution scheme are given in Table 2-2.

Because of the rugged topography along the eastern margin of the Dead Sea Rift, line-of-sight transmission to the Observatory in Amman from each remote seismic station was not possible. It was therefore necessary to transmit the signals from the North Array stations BURJ, JARJ, and RUMJ to SMAJ, where they are multiplexed and transmitted to a repeater station located at the Jordan Television transmitter site at Suweilih and subsequently transmitted to the Observatory (see Figure 2-2). Similarly, the South Array stations SALJ, KFNJ, and MKRJ transmit to the collector station MASJ and are multiplexed and transmitted directly to the Observatory in Amman.

At the Observatory, the data are continuously recorded on analog drum recorders. Gain settings are currently at $48 \mathrm{db}$ for all stations except for SMAJ, KFNJ, and MKRJ, which are set at $42 \mathrm{db}$. Universal Time (UT), transmitted from Radio Moscow (14996 KHz), is used to synchronize a crystal clock at the Observatory.

The analog drum charts are changed daily and the first arrivals (P-wave), second arrivals ( $\mathrm{S}$ wave), and duration are precisely measured and recorded on standard forms. The data are subsequently entered into a disk file on a microcomputer as input to a hypocenter location program. Events are identified on the basis of waveform shape and their occurrence on at least 
Figure 2-1: Location of Seismograph Stations of the Jordan Seismological Observatory

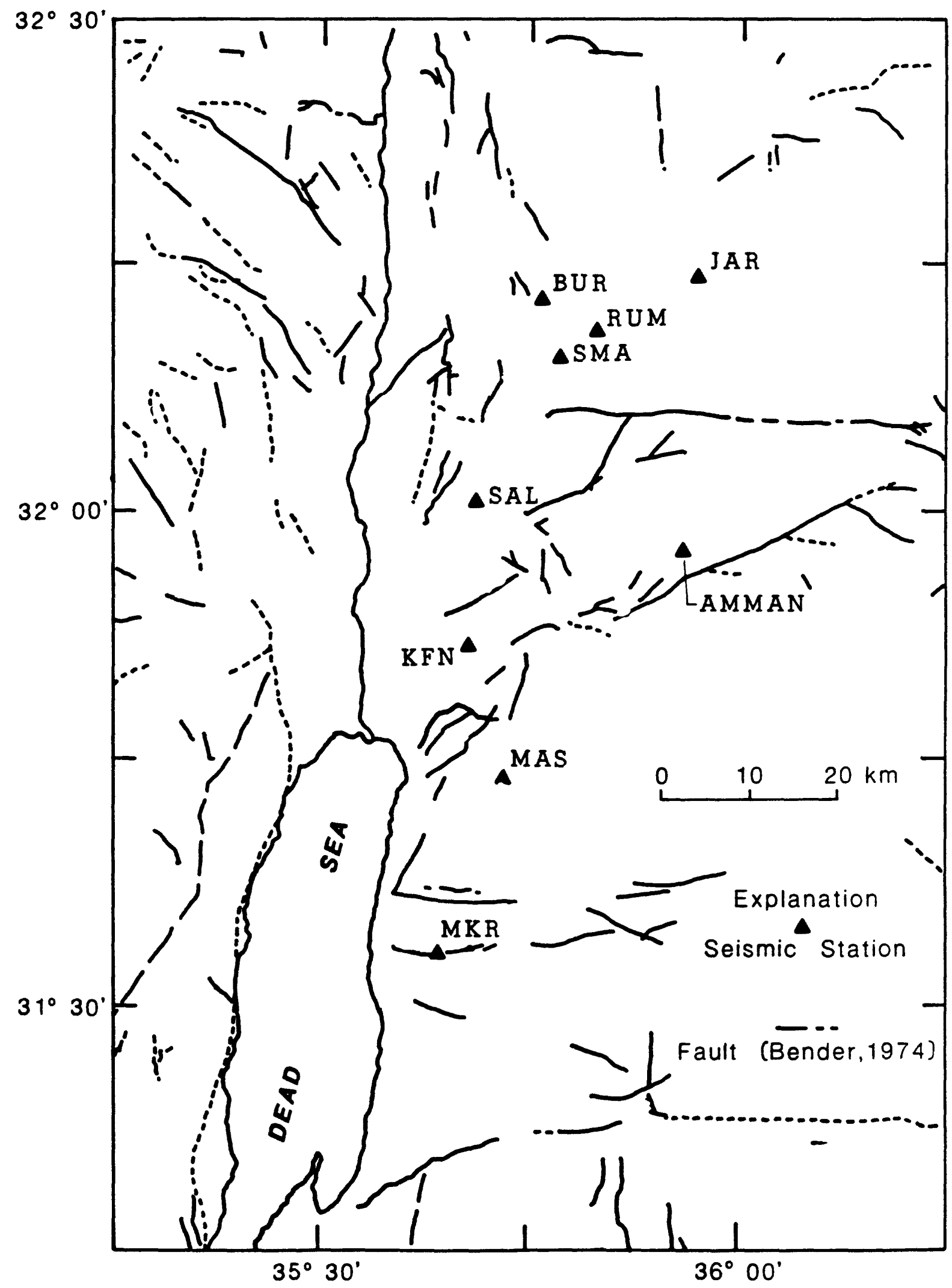


Table 2-1: Jordan Seismic Stations, Geographical Locations and Elevations

\begin{tabular}{ccccccc} 
STATION NAME & CODE NAME & \multicolumn{2}{c}{ LATITUDE } & \multicolumn{2}{c}{ LONGITUDE } & ELEVATION \\
\hline BURMA & BURJ & 32 & 12.81 & 35 & 45.76 & 520 \\
\hline JARASH & JARJ & 32 & 14.25 & 35 & 56.78 & 840 \\
\hline SUMIYA & SMAJ & 32 & 09.30 & 35 & 46.98 & 565 \\
\hline ER RUMMAN & RUMJ & 32 & 10.92 & 35 & 49.65 & 445 \\
\hline SALT & SALJ & 32 & 00.56 & 35 & 41.08 & 780 \\
\hline KAFREIN & KFNJ & 31 & 51.70 & 35 & 40.56 & -90 \\
\hline EL MASLUBIYA & MASJ & 31 & 43.74 & 35 & 43.10 & 822 \\
\hline MAKAWIR & MKRJ & 31 & 33.13 & 35 & 38.45 & 815 \\
\hline
\end{tabular}


Table 2-2: Radio Transmitter and Receiver Frequencies Assigned to Seismic Stations and Relays, Jordan Seismological Observatory

\begin{tabular}{|c|c|c|c|c|}
\hline $\begin{array}{l}\text { STATION } \\
\text { CODE }\end{array}$ & $\begin{array}{l}\text { RADIO } \\
\text { UNIT }\end{array}$ & TYPE & $\begin{array}{c}\text { FREQUENCY } \\
\text { (MHz) }\end{array}$ & $\begin{array}{l}\text { MODULATED } \\
\text { CARRIER }(\mathrm{Hz})\end{array}$ \\
\hline BURJ & $9 \mathrm{~T}$ & TRANSMITTER & 172.650 & 1020 \\
\hline JARJ & $3 \mathrm{~T}$ & TRANSMITTER & 168.825 & 1360 \\
\hline RUMJ & $5 T$ & TRANSMITTER & 168.850 & 1700 \\
\hline SMAJ & $\begin{array}{c}-- \\
9 \mathrm{R} \\
3 \mathrm{R} \\
5 \mathrm{R} \\
11 \mathrm{~T}\end{array}$ & $\begin{array}{c}\text { LINE } \\
\text { RECEIVER } \\
\text { RECEIVER } \\
\text { RECEIVER } \\
\text { TRANSMTTER }\end{array}$ & $\begin{array}{c}-- \\
172.650 \\
168.825 \\
168.850 \\
172.700\end{array}$ & $\begin{array}{c}680 \\
1020 \\
1360 \\
1700 \\
\text { SUMMED }\end{array}$ \\
\hline SUWEILIH & $\begin{array}{c}7 T \\
11 R\end{array}$ & $\begin{array}{c}\text { TRANSMITTER } \\
\text { RECEIVER }\end{array}$ & $\begin{array}{l}168.875 \\
172.700\end{array}$ & $\begin{array}{l}\text { SUMMED } \\
\text { SUMMED }\end{array}$ \\
\hline $\begin{array}{c}\text { NRA- } \\
\text { AMMAN }\end{array}$ & $\begin{array}{c}7 R \\
10 R\end{array}$ & $\begin{array}{l}\text { RECEIVER } \\
\text { RECEIVER }\end{array}$ & $\begin{array}{l}168.875 \\
172.675\end{array}$ & $\begin{array}{l}\text { SUMMED } \\
\text { SUMMED }\end{array}$ \\
\hline MKRJ & $2 \mathrm{~T}$ & TRANSMITTER & 168.800 & 2380 \\
\hline KFNJ & $4 \mathrm{~T}$ & TRANSMITTER & 168.825 & 2720 \\
\hline SALJ & $\overline{6 T}$ & TRANSMITTER & 168.850 & 3060 \\
\hline MASJ & $\begin{array}{c}\ddot{2 R} \\
4 R \\
6 R \\
10 T\end{array}$ & $\begin{array}{c}\text { LINE } \\
\text { RECEIVER } \\
\text { RECEIVER } \\
\text { RECEIVER } \\
\text { TRANSMTTER }\end{array}$ & $\begin{array}{c}-- \\
168.800 \\
168.825 \\
168.850 \\
172.675\end{array}$ & $\begin{array}{c}2040 \\
2380 \\
2720 \\
3060 \\
\text { SUMMED }\end{array}$ \\
\hline
\end{tabular}


Figure 2-2: Diagram of Radio Transmissions of the remote Seismic Stations to the Jordan Seismological Observatory

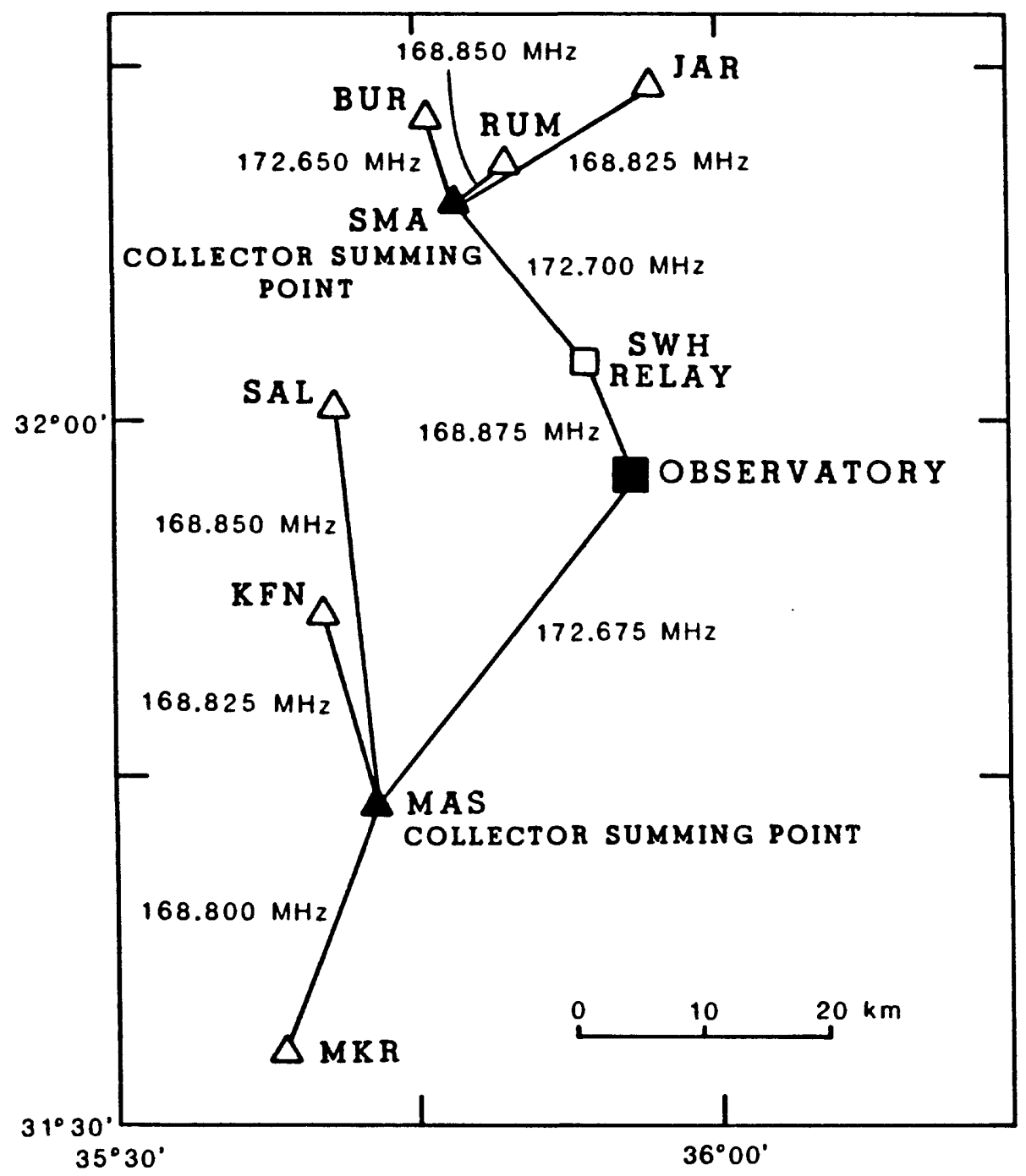


four records within a time window of ten seconds. Accuracy of measured arrival times ranges from 0.1 to 0.3 seconds, depending upon background noise (e.g., vehicular traffic, wind, sonic booms, livestock, and other cultural sources). The original seismograms are bound into weekly volumes, indexed, and archived for future reference at the Observatory. In addition, quarterly seismological bulletins have been issued since 1984 (Jordan Seismological Observatory, 1984abcde, 1985abc).

\section{Description of Automated Data Processing}

The automatic processing system for the Jordan Seismic Observatory was designed to achieve several objectives:

1. To detect and locate important earthquakes immediately.

2. To save digital copies of the seismogram for further analysis offline.

3. To operate at a remote location where telemetry to a central observatory was not feasible.

At the time we designed the system a number of automatic processing systems were operating on USGS networks in California, Hawaii and Washington, but none of these systems achieved all the objectives listed above. Furthermore, the most successful systems required expensive and complicated computer facilities backed by an experienced staff of seismologists, programmers, and engineers. With the rapid development of powerful small computer systems, we estimated that it would be possible to build a simpler system that would achieve the desired objectives with small computers, provided the number of stations analyzed were limited and the number of earthquakes occurring were not too large. We selected the Digital Equipment Corporation LSI $11 / 23$ for the system because it appeared to be the most reliable computer capable of doing the job and because it was compatible with other DEC equipment and maintenance services available in Jordan.

We built the system and software following the design of a similar system developed by Rex Allen and Jim Ellis at the USGS Menlo Park Laboratories (Allen, 1978). The system was designed to handle eight seismic stations telemetered to a central location. The analog seismic signals are digitized at $100 \mathrm{~Hz}$, with a precision of 12 bits, and earthquake events are timed and reported in real time. In addition, the digitized records of selected events are saved on a Winchester disk after the event occurs.

Two prototype systems have been built and successfully tested, one at the observatory in Amman and one in Menlo Park, California. Some problems were encountered during these tests. The automatic event detector does not work well in the presence of noise signals on the 
seismograph data channels. The most difficult noise signals are high frequency electronic noise introduced by faulty telemetry channels. This type of noise can produce many false events and overload the system. The solution to this problem requires that the telemetry be adjusted and maintained so that this noise source is minimized. A second problem is the transferability of software from one DEC computer to another. We thought that it would be easy to transfer important programs, such as the earthquake location program, from DEC computers such as the PDP 1170 and the PDP 1140 to the LSI 11/23, but because of subtle differences between these similar machines and their operating systems this job proved to be unexpectedly difficult. This problem has been solved for us by further advances in small computer systems and the extensive software development for these systems. The IBM PC and other computers designed to conform to the IBM architecture have been widely accepted in the business community and, more recently, scientific usage of these systems has greatly increased. It appears that this system may become a standard for the interchange of data and computer programs used in many scientific applications.

We have incorporated an IBM PC in the automatic processing system as a controller for the DEC computer and as an offline processor. A system of programs has been developed which reads the digital data saved on the 11/23, adjusts the picks, locates the earthquakes, and plots them on a Houston Instruments plotter.

The automatic system has now reached the stage that requires the participation of Jordanian seismologists to complete the installation in Jordan.

The first stage in the installation of the seismic computer system was completed in June, 1984. All components are Digital Equipment Corporation (DEC) hardware except for the Winchester disk/magnetic cartridge drive which is fully compatible with DEC. The system includes the following hardware:

1. DEC PDP 11/23 PLUS computer

2. DEC KDF11-BA PDP11/23 PLUS CPU module with boot ROMs, line clock and two serial ports.

3. DEC FPF11 floating point processor module

4. DEC MSV11-PL $512 \times 18$ bits memory modules

5. DSD890 Winchester disk, cartridge tape interface module: disk capacity is 32 megabytes

6. DEC ADV11-C 12 bit, 16-channel A/D converter module

7. DEC KWV11 real time clock module 


\section{DEC DLV11-J four port serial I/O module \\ 9. DEC VT100 video terminal \\ 10. DEC LA100 graphics line printer}

11. DEC TU58 cartridge tape serial I/O module (for alternate system boot)

Peripheral hardware:

1. Intertec microcomputer QD (CPM)

2. Intertec microcomputer Compustar

3. Intertec $\mathrm{K}$-system with 5 megabyte Winchester disk

4. Intertec DSS-10 external 10 megabyte Winchester disk

5. NEC 7710 printer (2)

6. Florida Data dot matrix printer

7. Houston Instruments HIPLOT 8-pen XY plotter

8. Houston Instruments HIPAD digitizer

The automatic system is now being operated in parallel with the analog system for testing and calibration. The data flow from the eight discriminators from the remote stations is shown in Figure 3-1.

\section{Determination of Epicenters and Local Magnitudes}

The Jordan seismic network has been in operation from September 1983. The original configuration of eight stations was slightly changed in November 1984 when the station previously at Hamta (HMTJ) was relocated to Jarash (JARJ). In addition, in May 1985 the Jordan Seismological Observatory became a member of the International Seismological Centre (ISC) whose headquarters are in Newbury, England.

All picked events are processed by a program which determines a preliminary hypocenter and origin time (if a convergent solution is obtained) and prints the data and solution in an appropriate format for bulletin publications. Many of the published events are probably explosions (e.g., quarry blasts), although the classification of these events is subjective and will require subsequent verification of occurrence and proximity to quarry sites or military training areas. Those earthquakes which are outside the area of interest (i.e., teleseisms) are not included in the bulletins. These events, however, are stored on floppy disks and hard copy and are archived for possible future analysis.

Preliminary hypocenter determinations are based on the method of Geiger (1912), which 
Figure 3-1: Schematic Showing Data Flow Through the Automatic Seismic System, Jordan Seismological Observatory

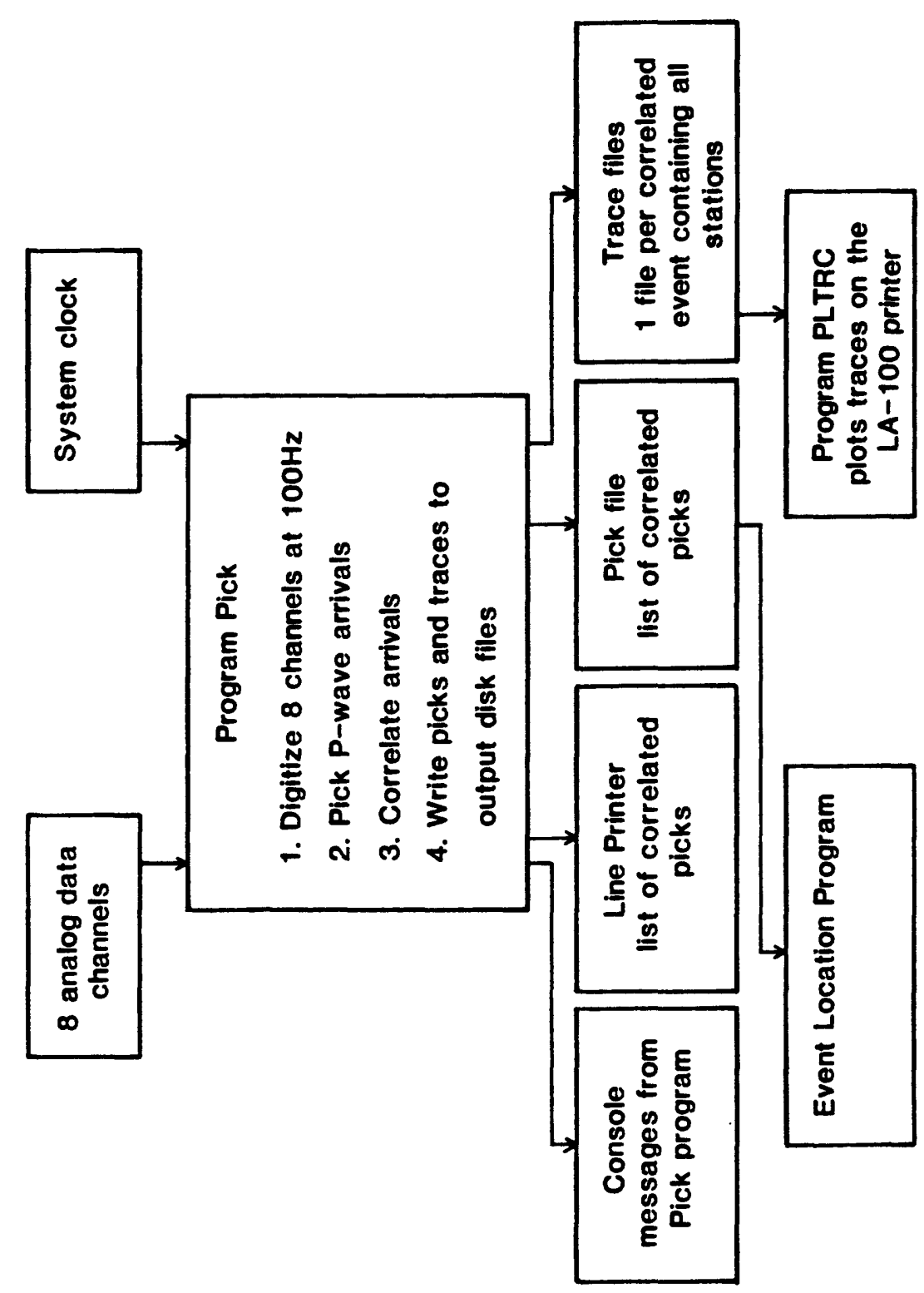


employs a least squares procedure to determine the origin time and hypocentral coordinates. Because the travel time equations are not as sensitive to focal depth variations as they are to the epicentral coordinates and origin time, the least squares procedure is restricted to these variables and focal depth is held constant. This procedure is repeated for a stepwise progression of depths and the focal depth estimated from that depth which minimizes residual travel time errors (Shapiro and Bath, 1977). The program now used is a modification of the program described by Shapiro (1983). It can accommodate up to eight layers, each of varying thickness above the half space. Both P- and S- arrivals are used in the location calculations, if available. The program also estimates the uncertainties in the calculated parameters. Location uncertainties are estimated as $\pm 3 \mathrm{~km}$ in EW and NS directions in most cases. It should be borne in mind, however, that the configuration of stations with respect to the epicenters is most favorable to the determination of epicenters in the vicinity of Amman. The velocity-depth function used to locate events is shown in Figure 4-1 and is based on seismic refraction data to subcrustal depths in the Dead Sea area (Ginzburg et al., 1979; Prodehl, personal communication).

The local magnitude $\mathrm{M}_{\mathrm{L}}$ of the seismic events reported in the Bulletins of the Jordan Seismological Observatory was estimated from the time duration of the seismic signal after the arrival of the S-wave according to the formula

$$
\begin{aligned}
M_{L}= & 0.7+0.0001 \text { (epicentral distance in } \mathrm{km} \text { ) }+ \\
& 1.54 \times \log \text { (Duration in seconds) }
\end{aligned}
$$

It needs to be emphasized that the reported magnitudes are relative and absolute calibration has not yet been attempted. In addition, it should be borne in mind that the values of the magnitude intercept and the slope of the line determined in a signal duration-magnitude relationship are a function of the instrument used in monitoring. We are working on an analysis of the accuracy of location and magnitudes of selected earthquakes. Our preliminary results show that large errors may be present in the locations calculated with the model used in this report. We suspect that these errors are primarily the result of the absence of station corrections. This problem requires further analysis.

\section{Overall Seismicity Pattern}

Earthquakes large enough to be felt attract most of the popular attention, but the many small microearthquakes (magnitude 3 and smaller) that occur between the larger earthquakes are also important to seismologists. Because of their frequency of occurrence, the-recording of microearthquakes can provide a large amount of critical data about the structure of the earth's crust and the tectonic stress within it. In addition, not all earthquakes originate from known 
Figure 4-1: Preliminary Velocity-depth Model used for Hypocenter Locations in Jordan

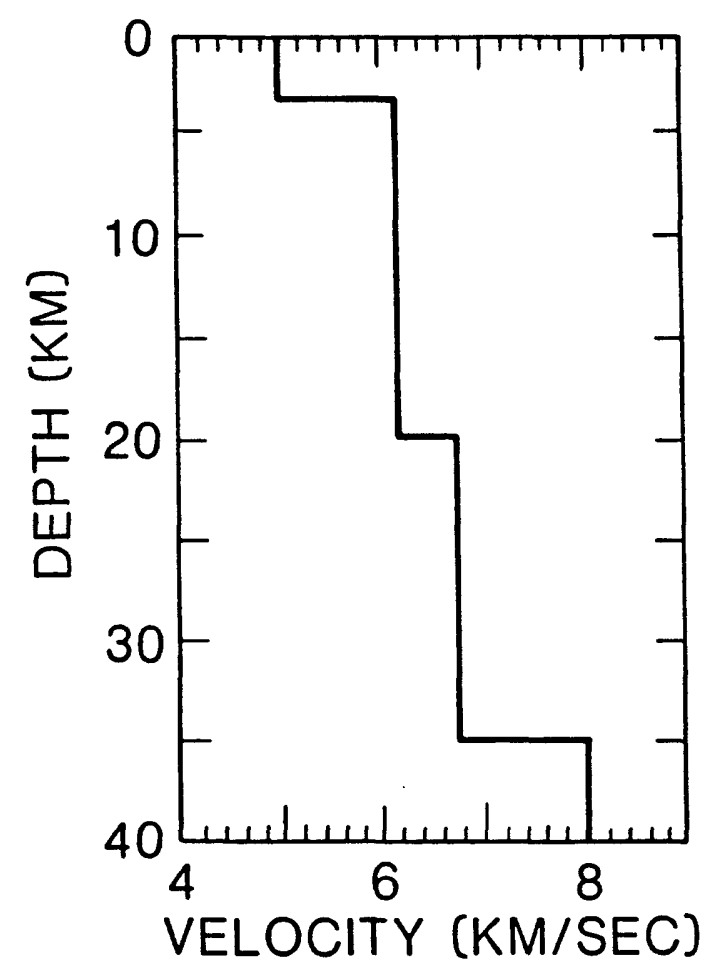


mapped faults. There are many active faults not visible at the surface, and the only way to discover their presence is by the monitoring of their activity, which is determined by the small earthquakes.

Figure 5-1 is a map of western Jordan showing the locations of the microseismic stations. Superimposed on this map are open dots that indicate the epicentral locations of microearthquakes located during the interval from April through June 1985. The diffuse pattern of seismicity is representative of the spatial microearthquake activity in western Jordan, although some of the events shown may be man-made explosions, particularly in the vicinity of the King Talal Dam, bracketed by the seismic stations Burma, Er Rumman and Sumiya.

The pattern of microearthquake activity is distributed in a broad zone from the Jordan River eastward rather than solely concentrated along the axis of the Dead Sea rift. Activity appears to be concentrated in east-west zones south of Maslubiya and in the vicinity of Makawir. In addition, activity occurs in a southwesterly trending direction just south of Amman. Several events are also located in the West Bank area and along the Dead Sea Rift itself. The determined magnitudes cluster around the value of $\mathrm{M}_{\mathrm{L}}=3$, although absolute calibration has not been completed.

With a few exceptions the epicentral map shows a strong correlation with mapped fault zones or their logical extensions when the 6-km diameter circle of location uncertainty is taken into consideration. The distributed pattern of seismicity suggests that in this region shear due to the differential motion of the Arabian Plate relative to Sinai is accommodated in part on easterly and northerly trending faults in a broad zone rather than just along the Dead Sea fault zone itself.

Additional information concerning the tectonic regime of the area is yet to be gleaned from a study of the polarities of the first arrivals of the P-waves. Although the station distribution in Jordan is not yet optimum, it should be possible to use additional data from neighboring seismic stations to do focal mechanism studies.

\section{Conclusions and Recommendations}

The establishment and operation of a microseismic network in Jordan will make important contributions to the understanding of earthquakes and tectonics in this region and will ultimately help to assess and reduce the earthquake hazard. An initial eight-station array has been installed in Jordan, complemented by an automatic computer system. To achieve the spirit and original goals of the project (Kovach, Andreasen, and Healy, 1981), we propose the completion of the installation of a 32-station network in Jordan, including ten three-component stations. This 
Figure 5-1: Microseismicity of Western Jordan, April through June 1985.

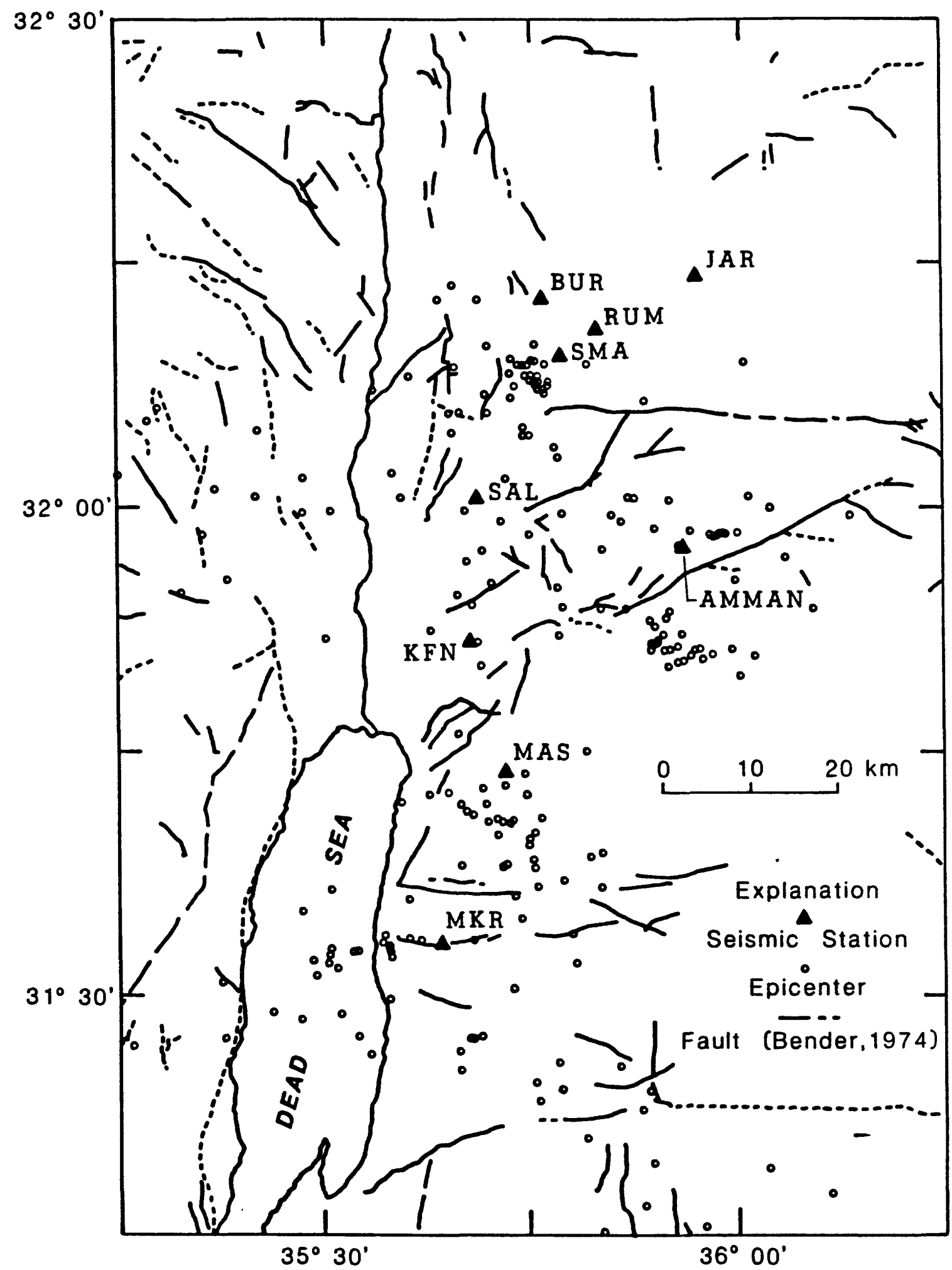


would provide a network for continuous monitoring of all areas in Jordan. A plan for the installation of additional stations in Jordan is shown in Figure 6-1.

One of the more important objectives of a seismic network in Jordan is the possibility of educational benefits. Paramount in our plans to establish a network was that training be provided so that maintenance and data analyses would be carried out by Jordanians. The goal here can be simply stated: the strengthening of geophysical sciences in Jordan.

Some comments concerning the automatic network appear to be in order. In the original proposal for the network we expected to use at least one DEC 11/23 PLUS computer for each eight stations or "clusters" in the network, with each cluster linked to a central computer to collate, store, and process the data. We realized that some of the cluster computers might be located away from the observatory at remote locations where we could not establish reliable telemetry. At these remote sites more than one 11/23 PLUS processor might be required. Recently, the IBM PC type systems have had important applications to our work. The IBM PC has a huge base of powerful software that makes these systems extremely versatile. Most of this software was written for applications in business and management but in the last year there has been a rapid increase of scientific and data acquisition software. W.H.K. Lee and his associates at the USGS in Menlo Park have developed Earthquake Analysis software for the IBM PC, and all of this software will be available to us if we use the IBM PC systems. It is much easier to train novice users to use the IBM PC with the DOS operating system than the DEC 11/23 PLUS with the RT11 and RSX operating systems. The IBM Portable PC can be purchased in the United States for about the same price as a standard computer terminal, and it is an ideal smart terminal for the DEC VAX series of computers.

\section{Acknowledgments}

The installation and operation of the microseismic network in Jordan is due to the enthusiastic support of the officials and staff of the Natural Resources Authority of the Hashemite Kingdom of Jordan and the United States Agency for International Development. Special acknowledgment is given to the previous Director General Y. Nimri, M. Abu Ajamieh and K. Kaysi of the Natural Resources Authority. 
Figure 6-1: A Proposed Plan for Additional Stations to be Added to the Jordan Seismological Observatory Network

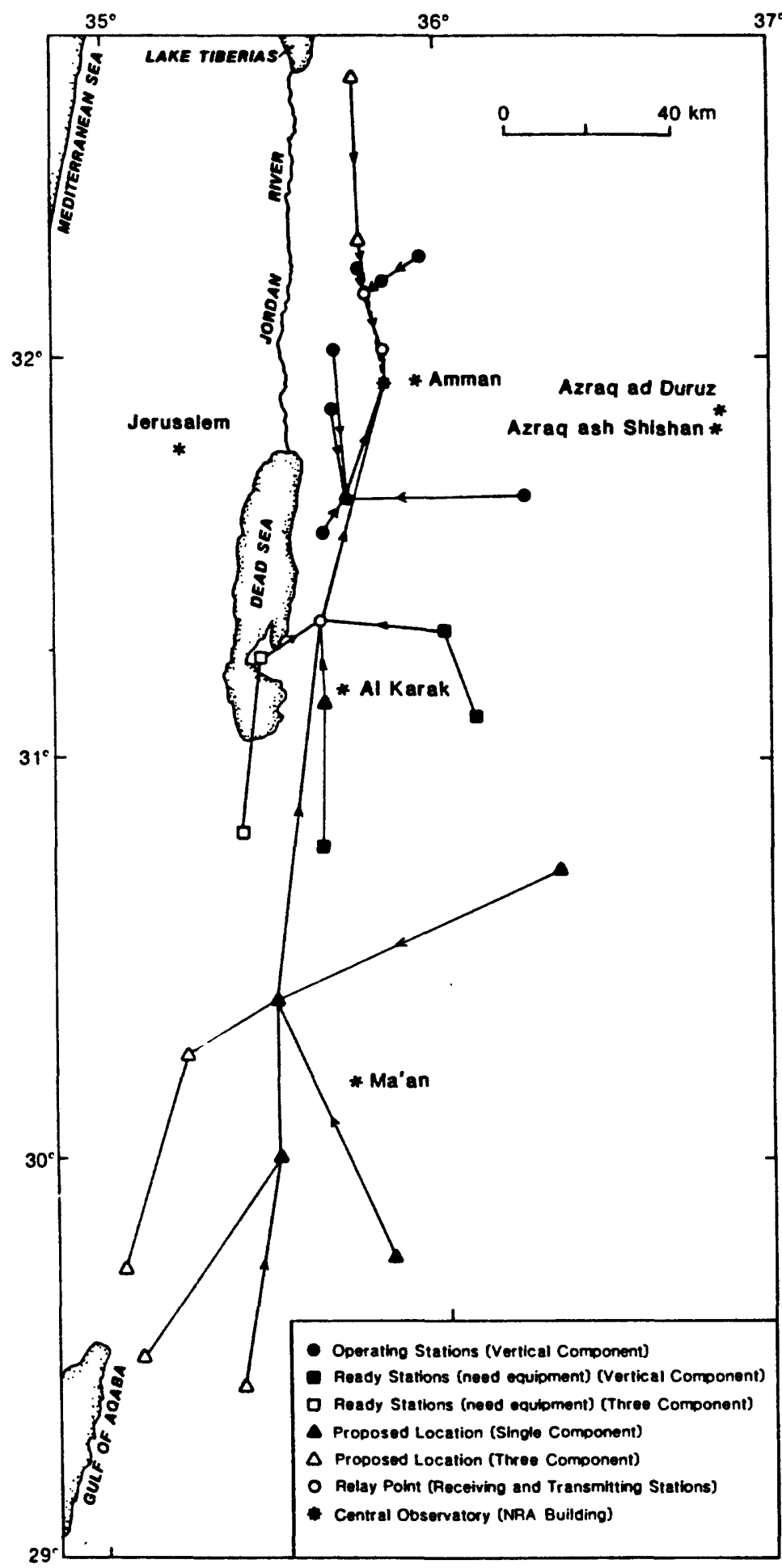




\section{References}

1. Allen, Rex V., Automatic Earthquake Recognition and Timing from Single Traces, Bull. Seismological Soc. Amer., 68, 1521-1532, (1978).

2. Arieh, E., Seismicity of Israel and Adjacent Areas, Geol. Surv. Israel Bull., 43, 1-14, (1967).

3. Bender, F., Geology of the Arabian Peninsula-Jordan, U.S. Geological Survey Professional Paper, No. 560-I, (1974).

4. Ben-Menahem, A., Variation of Slip and Creep Along the Levant Rift Over the Past 4500 Years, in R. Freund and Z. Garfunkel (Editors), The Dead Sea Rift, Tectonophysics, 80, 183-197, (1981).

5. Ben-Menahem, A., and Aboodi, E., Micro and Macroseismictiy of the Dead Sea Rift and Off-coast Eastern Mediterranean, Tectonophysics, 80, 199-233, (1981).

6. Ben-Menahem, A., Nur, A., and Vered, M., Tectonics, Seismicity and Structure of the Afro-Eurasian Junction - the Breaking of an Incoherent Plate, Phys. Earth Planet Inter., 12, 1-50, (1976).

7. Ben-Menahem, A., Aboodi,E., Vered, M., and Kovach, R.L., Rate of Seismicity of the Dead Sea Region Over the Past 4000 years, Phys. Earth Planet. Inter., 14, 17-27, (1977).

8. Freund, R., Zak, I., \& Garfunkel, Z., Age and Rate of the Sinistral Movement Along the Dead Sea Rift, Nature, 220, 253-244, (1968).

9. Geiger, L., Probability Method for the Determination of Earthquake Epicenters from the Arrival only, (translated from German) Bulletin of Saint Louis University, 8, 56-71, (1912).

10. Ginzburg, A., Makris, J., Fuchs, K., Prodehl, C., Kaminski, W., and Amitai, U., A Seismic Study of the Crust and Upper Mantle of the Jordan-Dead Sea Rift and their Transition Towards the Mediterranean Sea, J. Geophys. Res., 84, 1569-1582, (1979).

11. Girdler, R.W. \& Styles, P., Two-stage Red Sea Floor Spreading, Nature, 247, 7-11, (1974).

12. Hatcher, R.D., Zietz, I., Regan, R.D., and Abu Ajamieh, Sinistral Strike-slip Motion on the Dead Sea Rift: Confirmation from New Magnetic Data, Geology, 10, 458-461, (1981).

13. Jordan Seismological Observatory, Earthquakes in Jordan and Adjacent Areas, September to December 1983, Natural Resources Authority, Hashemite Kingdom of Jordan, Jordan Seismological Observatory, Geophysics Division, Bull., No. 1, 1-112, (1984a).

14. Jordan Seismological Observatory, Earthquakes in Jordan and Adjacent Areas, January to March 1984, Natural Resources Authority, Hashemite Kingdom of Jordan, Jordan Seismological Observatory, Geophysics Division, Bull.,-No. 2, 1-105, (1984b).

15. Jordan Seismological Observatory, Earthquakes in Jordan and Adjacent Areas, April to June 1984, Natural Resources Authority, Hashemite Kingdom of Jordan, 
Jordan Seismological Observatory, Geophysics Division, Bull., No. 3, 1-151, (1984c).

16. Jordan Seismological Observatory, Earthquakes in Jordan and Adjacent Areas, July to September 1984, Natural Resources Authority, Jordan Seismological Observatory, Geophysics Division, Bull., No. 4, 1-105, (1984d).

17. Jordan Seismological Observatory, Earthquakes in Jordan and Adjacent Areas, October to December 1984, Natural Resources Authority, Hashemite Kingdom of Jordan, Jordan Seismological Observatory, Geophysics Division, Bull., No. 5, 1-106, (1984e).

18. Jordan Seismological Observatory, Earthquakes in Jordan and Adjacent Areas, January to March 1985, Natural Resources Authority, Hashemite Kingdom of Jordan, Jordan Seismological Observatory, Geophysics Division, Bull., No. 6, 1-70, (1985a).

19. Jordan Seismological Observatory, Earthquakes in Jordan and Adjacent Areas, April to June 1985, Natural Resources Authority, Hashemite Kingdom of Jordan, Jordan Seismological Observatory, Geophysics Division, Bull., No. 7, 1-92, (1985b).

20. Jordan Seismological Observatory, Earthquakes in Jordan and Adjacent Areas, July to September 1985, Natural Resources Authority, Hashemite Kingdom of Jordan, Jordan Seismological Observatory, Geophysics Division, Bull., No. 8, 1-77, (1985c).

21. Kovach, R.L., What is the Rate of Seismic Slip Along the Dead Sea Rift?, Int. Symp. Rift Zones of the Earth-The Dead Sea Rift, September 10-20, 34, Jerusalem, (1979).

22. Kovach, R.L., Andreasen, G.E. and Healy, J.H., A Proposal for the development and Installation of the Jordan Seismic System (JSS) with Emphasis on Earthquake Risks, Crustal Structure and Geothermal Energy, USGS Project Report, Jordan Investigations, IR-JO-13, 1-35, (1981).

23. Kovach, R.L., Andreasen, G.E. and Gettings, M., Microseismicity of Western Jordan--Clues to the Differences in the Dead Sea Rift Slip Rate, EOS, Trans. American Geophys. Union, 66, 954, (1985).

24. North, R.G., Seismic Slip Rates in the Mediterranean and Middle East, Nature, 252, 560-563, (1974).

25. Shapiro, A., A Guide for Using LME 83, IPRG Report Z1/567/, 79-(16), 1-13, 2 appendices, (1983).

26. Shapiro, A., and Bath, M., Short Distance Hypocenter Location in a Layered Media, Seis. Inst. Uppsala, Sweden, Report 2-77, (1977).

27. Wu, F.T., Karcz, I., Arieh, E., Kafri, U., and Peled, U., Microearthquakes along the Dead Sea Rift, Geology, 1, 159-161, (1973). 